\title{
Management of COVID-19 Infected Patients in Pregnancy and Puerperium
}

\author{
Basant Sharma ${ }^{1}$, Ganesh Dangal ${ }^{2}$, Bandana Khanal ${ }^{1}$, Siddeshwar Angadi ${ }^{3}$ \\ ${ }^{1}$ Department of Obstetrics and Gynecology, Chitwan Medical College, Bharatpur \\ ${ }^{2}$ Department of Obstetrics and Gynecology, Kathmandu Model Hospital, Kathmandu \\ ${ }^{3}$ School of Nursing, Chitwan Medical College, Bharatpur
}

Received: May 15, 2020

Accepted: May 31, 2020

\begin{abstract}
COVID-19 is a pandemic affecting every group of people. Pregnancy itself is a partially immune compromised state, so chance of aggravation of symptom supposed to be more in pregnancy. Prevention is the best way to get away from this disease. Good hygiene, supportive care and possible mechanical ventilation for severe case are required. There is no proven role of antibiotic, antiretroviral and steroids. There is no proven vertical transmission. Baby has to be kept in isolation and breast milk can be expressed and given to newborn.
\end{abstract}

Keywords: COVID-19, pandemic, pregnancy.

Citation : Sharma B, Dangal G, Khanal B, Angadi S. Management of COVID-19 Infected Patients in Pregnancy and Puerperium. Nep J Obstet Gynecol. 2020;15(30):76-78. DOI: 10.3126/njog.v15i1.29347

\section{INTRODUCTION}

After the emergence SARS-CoV-2 virus the COVID-19 has become pandemic affecting all age groups of people. Pregnancy itself is a partially immunosuppressed state and any viral or bacterial pneumonia can be life-threatening during pregnancy. ${ }^{1}$ This disease causes more adverse effects in preexisting diseases like diabetes, hypertension, COPD and cancer. ${ }^{2}$ Other corona viruses like Severe Acute Respiratory (SARS-CoV) and middle-east respiratory syndrome (MERS-CoV) are from same family. There are no definite data of mortality or morbidity from COVID-19 but there are reports of mortality of around 37\% in Middle-East Respiratory Syndrome (MERS-CoV) and as high as 25\% in Severe Acute Respiratory (SARS-CoV) pregnant women. ${ }^{3,4}$

Few clinical experiences from world have shown that iatrogenic preterm delivery could have been increased but requires more data to be statistically significant. Emerging evidence now suggests that vertical transmission is probable, but the proportion of pregnancies affected and the significance to

\section{CORRESPONDENCE}

\section{Dr Basant Sharma}

Department of Obstetrics and Gynecology, Chitwan Medical College, Chitwan

Email:sharma.basant@cmc.edu.np; Phone: +977-9851220907 the neonate has yet to be proven. Effect on early pregnancy is unknown. Rate of spontaneous miscarriages or intrauterine fetal deaths are not clear till date. Teratogenicity of virus to fetus are not found in these limited studies..$^{5,6}$

\section{Preventive measures during pregnancy}

Frequent hand washing, avoiding outdoor works, crowded places and social gathering are utmost for pregnant lady. Contact with people from hot spot areas is to be restricted. Immediate consultation with obstetrician and regular temperature monitoring in presence of symptoms like dyspnea, fever, and cough are essential. Pregnant lady with travel history to hot spot area and clinical suspicion of infection should be kept in isolation room with negative pressure for at least two weeks; and psychological support is to be given to avoid depression and anxiety in pregnant lady. ${ }^{4,7}$ 


\section{Diagnosis of COVID-19}

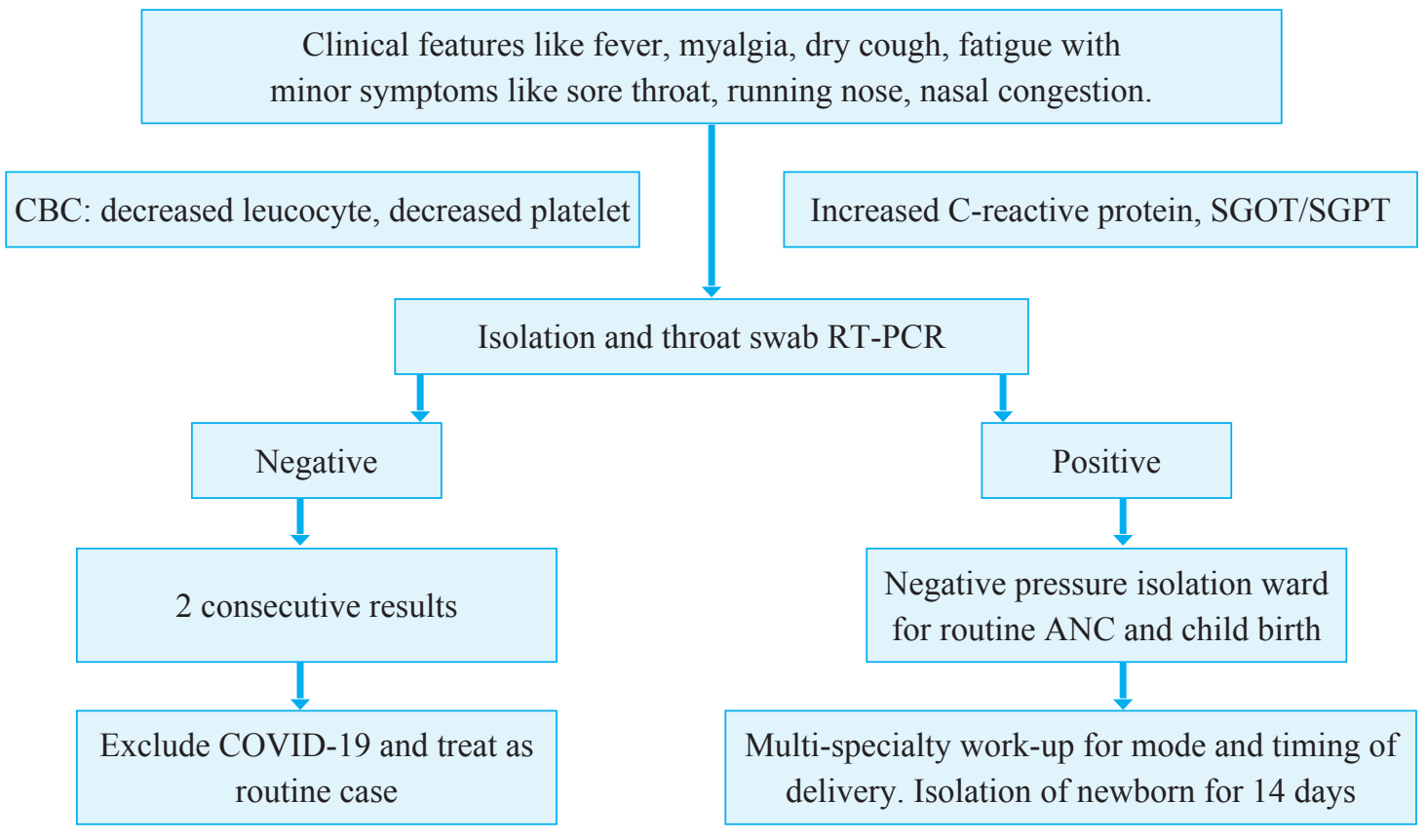

\section{Management of COVID-19 in pregnancy}

Anyone who has history and symptoms suggestive of COVID-19 should be treated as positive unless proven otherwise by laboratory test. It should be undertaken by a multidisciplinary team in designated tertiary hospitals with effective isolation facilities and protection equipment. Supportive care like adequate rest, sleep along with plenty of fluid and highly nutritious diet if sufficient for mild and asymptomatic case. If required high flow oxygen and mechanical ventilator support with fluid and electrolyte balance are given in severe cases.

Antibiotics are not effective for treatment of COVID-19. So, unnecessary usage of drug is better to be avoided. In cases of secondary alveolar damage caused by virus, or if there is suspected or confirmed secondary bacterial infection broad spectrum antibiotics can be used. ${ }^{7}$

Antiretroviral drugs are not recommended by FDA but Chinese health officials recommend use of alpha-interferon inhalation but better avoided in early pregnancy to avoid fetal restriction. Lopinavir/ ritonavir can have some positive effect. ${ }^{7}$ Corticosteroid like methylprednisolone is not to be used routinely as it obstructs the clearance of virus from body but can be used for short period (3-5 days) in severe dyspnea and hypoxemia. ${ }^{?}$

\section{Delivery: when and how?}

It should be specific to each patient considering the severity of disease, gestational age, fetal condition and maternal comorbid conditions like diabetes, heart disease, and hypertension. For mild and asymptomatic cases with normal fetal condition, pregnancy can be continued till term under close surveillance. But for critical cases, safety of mother and child may be jeopardized by continuing the pregnancy. In such scenario, prompt delivery is required. Age of viability of fetus is a consideration before termination. If gestational age is too early, proper counseling is required. ${ }^{7}$ Mode of delivery is according to obstetric indication. As there are no proven data for transmission of virus via vaginal route, vaginal delivery should be considered unless contraindicated. After the onset of labour, water and clear fluid should be encouraged orally. If intravenous fluid has to be used, it should be less than $125 \mathrm{ml} /$ hour of $5 \%$ dextrose. Mobility during labour should be advised only after social distancing. Oxytocin augmentation is recommended to shorten labour delivery interval in first stage of labour. Use of high flow oxygen with nasal prongs or face masks during labour for fetal indication should be avoided unless and until there is maternal indication. Labour analgesia can be according to availability but use aerosol generating anesthesia should be minimized. Epidural analgesia 
is beneficial even if patient requires cesarean section later. Pain management should be done properly to prevent restlessness, agitation and yelling. Pushing in second stage of labour should be short as far as possible. Delivery in bath tub is discouraged and birth position is mother's choice. For critically ill patients, cesarean is advocated under general anesthesia (GA). ${ }^{8}$ Placental tissue can be disposed as bio hazardous waste after testing for COVID-19.

\section{Neonatal care}

Few obtained data suggest there is less chances of transplacental transmission. Delayed cord clamping is advocated as there is least chance of vertical transmission. ${ }^{9}$ Newborn resuscitation should be performed two meters away from mother. Newborns are kept in isolation for 14 days minimum with careful monitoring to avoid transmission by droplet after delivery. It is advised to use a breast pump to minimize the risk of transmission. ${ }^{10,11}$ By this, the baby will get the nutrients of breast milk. Strict hand hygiene and cleaning of breast prior pumping are necessary.The exposure of infants to maternal body fluids should be minimum during labor. ${ }^{11}$

\section{CONCLUSIONS}

A well-planned clinical management and support to the pregnant woman by using adequate protective equipment by the health care workers should be our aim. A team of obstetrician, mid-wife, neonatologist, anesthesiologist, critical care expert and entire health staff is basic requirement. Treatment of COVID-19 positive woman is to be done in an isolation ward, operation room, delivery room and postnatal ward preferably with negative pressure setting. Mobility should be allowed with social distancing during labour with proper labour analgesia. There is less chance of vertical transmission but neonate should be kept in isolation for 14 days. Breast milk can be given to baby after expressing breast milk.

\section{REFERENCES}

1. Mathad JS, Gupta A. Pulmonary infections in pregnancy. Semin Respir Crit Care Med. 2017;38:174-84. DOI: 10.1055/ s-0037-1602375

2. WHO. Coronaviruses (COVID-19). Accessed on March 25, 2020. Available from: https;//www.who.int/emergencies/diseases/novel-coronavirus-2019.

3. WHO. Middle East respiratory syndrome coronavirus (MERS-CoV) [WHO website]. Accessed on March 18,2020. https//www.who.int/emergencies/mers-cov/en/.

4. Wong SF, Chow KM, Leung TN, Ng WF, Ng TK, Shek CC, et al. Pregnancy and perinatal outcomes of women with severe acute respiratory syndrome. Am J Obstet Gynecol. 2004;191:292-7. DOI: 10.1016/j.ajog.2003.11.019

5. Chen H, Guo J, Wang C,Luo F, Yu X, Zhang W,et al. Clinical characteristics and intrauterine vertical transmission potential of COVID-19 infection in nine pregnant women: a retrospective review of medical records. Lancet. 2020;395(10226):80915. doi: 10.1016/S0140-6736(20)30360-3 Epub 2020 Feb 12

6. Zhu H, Wang L, Fang C, PengS, ZhangL, Chang G, et al Clinical analysis of 10 neonate born to mothers with 2019 nCoV pneumonia. Transl Pediatr. 2020;9(1):51-60. DOI: https://doi.org/10.21037/tp.2020.02.06

7. Liang H, Acharya G. Novel corona virus disease (COVID-19) in pregnancy: what clinical recommendations to follow? Acta Obstet Gynecol Scand. 2020. DOI: https://doi.org/10.1111/ aogs. 13836 .

8. Rochwerg B, Brochard L, Elliott MW, Hess D, Hill NS, Nava $\mathrm{S}$, et al. Official ERS/ATS clinical practice guidelines: Noninvasive ventilation for acute respiratory failure. Eur Respir J. 2017;50(2):1602426. DOI: 10.1183/13993003.02426-2016

9. Global surveillance for COVID-19 caused by human infection with COVID-19 virus Interim guidance, WHO. 20 March 2020.Accessed 19 May 2020.Available at: https://apps.who. int/iris/handle/10665/331506

10. Centers for Diseases Control and Prevention. Pregnancy and Breastfeeding. Accessed 19 Feb 2020. Available fromhttps:/ www.cdc.gov/coronavirus/2019-ncov/need-extra-precautions/pregnancy-breastfeeding.html

11. Rasmussen SA, Smulian JC, Lednicky JA, Wen TS, Jamieson DJ. Coronavirus Disease 2019 (COVID-19) and pregnancy: what obstetricians need to know. Am J Obstet Gynecol. 2020;222(5):415 26. doi:10.1016/j.ajog.2020.02.017 